\title{
Idiopathic Scoliosis: Genetic and Environmental Aspects
}

\author{
FRANCES V. DE GEORGE and ROBERT L. FISHER*
}

\begin{abstract}
From the Department of Medical Genetics, University of Wisconsin, Madison, Wisconsin, and The Hospital for Special Surgery New York, New York, U.S.A.
\end{abstract}

Although numerous clinical studies of 'idiopathic' scoliosis have been reported (McCarroll and Costen, 1960; Riddle and Roaf, 1955; Stearns, Jo-Yun Tung Chen, McKinley, and Ponseti, 1955), the aetiology of this condition remains obscure. Such diverse explanations as abnormal vertebral growth, spinal muscle imbalance, postural alterations, and endocrine and metabolic disturbances have found adherents (American Orthopedic Association Research Committee, 1941). The many case reports of specific families having several affected members have implied that hereditary factors might be significant in this disorder (Garland, 1934; Molski, 1957; Sidler, 1938; Staub, 1922), and some investigators have even suggested simple modes of inheritance (Faber, 1936; WynneDavies, 1965). In spite of this previous work, there remains no convincing evidence that idiopathic scoliosis is predominantly influenced by either genetic or environmental factors.

This study was undertaken to determine whether idiopathic scoliosis could be demonstrated to follow a predictable mode of inheritance, or to associate with maternal age or birth order.

\section{Materials and Methods}

The study population consisted of 1378 patients with idiopathic scoliosis, seen in the Hospital For Special Surgery Scoliosis Clinic, New York City, from January 1935 to June 1965. The diagnosis of idiopathic scoliosis in this study was considered only in patients having lateral spinal curvatures of at least ten degrees (Cobb, 1948), and without evidence of underlying conditions known to be associated with scoliosis, e.g. poliomyelitis, neurofibromatosis, and congenital vertebral anomalies.

Each patient was sent a questionnaire requesting the following information: birth dates and scoliosis status of mother, father, and sibs; abnormalities in the patient and his sibs; patient's birth date, birthweight, and whether

Received May 9, 1967.

* Present address: Newington Children's Hospital, Newington, Conn., U.S.A. twin born. The response to the questionnaire (December, 1965) is presented in Table I according to clinical status of the patients, active or inactive, i.e. whether or not they were being followed in the Scoliosis Clinic at this time. The questionnaire was received by 845 patients, of which $510(60 \%)$ answered. These replies were received predominantly from active patients, while the undelivered group was characterized by a higher proportion of inactive patients, reflecting the transient population of the New York metropolitan area. No differences occurred in the proportions of males and females within the three questionnaire groups relative to clinical status $(p=>0 \cdot 50)$. The answered group may be considered to be a representative sample of the total study population, since no differences in nationality, background, sex, age first noted, severity of curvature, or treatment outcome were found between patients answering and not answering the questionnaire.

Only data regarding the answered group were utilized in the subsequent analysis. Information on when age curvatures were first noted was derived from the medical records, all other data were obtained from the questionnaire, since the questionnaire replies provided a more uniform and complete source of information regarding parental ages, birth order, completed sibships, and scoliosis status of sibs. The latter was verified from the medical records. Among the 510 patients in the answered group it was necessary to exclude 51 from analysis to provide a more homogeneous sample for investigation. Excluded were 26 non-Caucasian patients, 15 patients having an age at which scoliosis was first noted over 22 years, and 10 patients with questionable diagnosis after review of the medical records. 13 twins were removed from the single-born sample to be analysed separately.

The study group for analysis consisted of $446 \mathrm{Cau}-$ casian propositi, 54 males and 392 females, with an established diagnosis of idiopathic scoliosis, whose curvatures were first noted before the age of 23 years. In view of the known difference in sex incidence of idiopathic scoliosis, males and females were analysed separately.

A twin poll was conducted among the propositi. In the total population, 17 twin pairs were identified through their medical records and/or the questionnaire. 251 
TABLE I

SUMMARY OF QUESTIONNAIRE RESPONSE

\begin{tabular}{|c|c|c|c|c|c|c|c|c|c|c|c|c|c|}
\hline \multirow{4}{*}{ Questionnaire } & \multicolumn{8}{|c|}{ Clinic Status } & \multirow{2}{*}{\multicolumn{4}{|c|}{$\begin{array}{l}\text { Total Active and } \\
\text { Inactive Propositi }\end{array}$}} & \multirow{4}{*}{ Total } \\
\hline & \multicolumn{4}{|c|}{ Active } & \multicolumn{4}{|c|}{ Inactive* } & & & & & \\
\hline & \multicolumn{2}{|c|}{ Male } & \multicolumn{2}{|c|}{ Female } & \multicolumn{2}{|c|}{ Male } & \multicolumn{2}{|c|}{ Female } & \multicolumn{2}{|c|}{ Male } & \multicolumn{2}{|c|}{ Female } & \\
\hline & No. & $o_{0}$ & No. & ${ }_{0}^{\circ}$ & No. & $\%$ & No. & $\%$ & No. & ${ }_{0}^{\circ}$ & No. & \% & \\
\hline $\begin{array}{l}\text { Answered } \\
\text { Not answered } \\
\text { Undelivered }\end{array}$ & $\begin{array}{l}54 \\
33 \\
23\end{array}$ & $\begin{array}{l}49 \\
30 \\
21\end{array}$ & $\begin{array}{l}365 \\
172 \\
116\end{array}$ & $\begin{array}{l}56 \\
26 \\
18\end{array}$ & $\begin{array}{l}10 \\
24 \\
56\end{array}$ & $\begin{array}{l}12 \\
26 \\
62\end{array}$ & $\begin{array}{r}81 \\
106 \\
338\end{array}$ & $\begin{array}{l}16 \\
20 \\
64\end{array}$ & $\begin{array}{l}64 \\
57 \\
79\end{array}$ & $\begin{array}{l}32 \\
28 \\
40\end{array}$ & $\begin{array}{l}446 \\
278 \\
454\end{array}$ & $\begin{array}{l}38 \\
24 \\
38\end{array}$ & $\begin{array}{l}510 \\
335 \\
533\end{array}$ \\
\hline Total & 110 & 100 & 653 & 100 & 90 & 100 & 525 & 100 & 200 & 100 & 1178 & 100 & 1378 \\
\hline
\end{tabular}

* Patients no longer being followed in the Scoliosis Clinic.

located and two unlike sex pairs refused participation. Both members of the remaining 14 pairs were examined clinically and radiographically, and a blood specimen was obtained. Zygosity diagnosis was established on the basis of determinations of 18 blood group antigens, morphological traits, and dermatoglyphic studies (Osborne and De George, 1959).

\section{Results}

Single-born Sample. There were 52 males and 383 female propositi* of which $29 \%$ and $17 \%$, respectively, had a parent affected with scoliosis (Table II). There was a preponderance of affected mothers relative to affected fathers in both male and female propositi, as expected. In this study, males had a higher percentage of affected parents than did females.

TABLE II

AFFECTED FATHERS AND MOTHERS OF PROPOSITI

\begin{tabular}{|c|c|c|c|c|c|c|c|}
\hline \multirow[t]{2}{*}{ Propositi } & \multirow[t]{2}{*}{ No. } & \multicolumn{2}{|c|}{$\begin{array}{l}\text { Affected } \\
\text { Fathers }\end{array}$} & \multicolumn{2}{|c|}{$\begin{array}{l}\text { Affected } \\
\text { Mothers }\end{array}$} & \multicolumn{2}{|c|}{$\begin{array}{l}\text { One Paren } \\
\text { Affected* }\end{array}$} \\
\hline & & No. & $\%$ & No. & $\%$ & No. & $\%$ \\
\hline $\begin{array}{c}\text { Male } \\
\text { Female }\end{array}$ & $\begin{array}{r}52 \\
383\end{array}$ & $\begin{array}{r}5 \\
19\end{array}$ & $\begin{array}{r}10 \\
5\end{array}$ & $\begin{array}{l}10 \\
48\end{array}$ & $\begin{array}{l}19 \\
12\end{array}$ & $\begin{array}{l}15 \\
67\end{array}$ & $\begin{array}{l}29 \\
17\end{array}$ \\
\hline
\end{tabular}

* There were no propositi with both parents affected.

In the analysis of sibs, only complete sibships with all sibs over 16 years of age were included to allow for the variable onset age of scoliosis. (Scoliosis was first noted in over $90 \%$ of the total study group before the age of 16 years.) Among 296 sibships fulfilling these criteria, there were 44 sibships of male and 252 of female propositi with $7 \%$ and $10 \%$ affected sibs, respectively. On the basis of recessive inheritance, the expected ratio of unaffected to affected sibs is $3: 1$; combining males

* The term, propositi, refers in this study to index cases. and females, the ratio observed in this study is $429: 40$, or $10 \cdot 7: 1$ by the simple sib method ( $\mathrm{Li}$, 1961).

TABLE III

DISTRIBUTION OF PROPOSITI BY MATERNAL AGE

\begin{tabular}{c|cc}
\hline & \multicolumn{2}{|c}{ Propositi } \\
\cline { 2 - 3 } Maternal Age-group & Observed & Expected* $^{*}$ \\
\hline $15-19$ & 4 & 21 \\
$20-24$ & 64 & 113 \\
$25-29$ & 136 & 133 \\
$30-34$ & 128 & 88 \\
$35-39$ & 64 & 40 \\
$40-44$ & 8 & 9 \\
\hline Total & 404 & 404 \\
\hline
\end{tabular}

$\chi^{2}=68.43,5$ d.f., $\mathrm{p}<0.001$

* Expected values calculated from U.S. Vital Statistics for New York State white live-born births 1938-1956. Only propositi born during this period are included in this calculation.

The Hospital for Special Surgery is an orthopaedic centre exclusively, therefore other diagnostic groups within the hospital population would not afford proper control data. Since the propositi of this study are derived predominantly from New York State, the latter statistics provide the most appropriate available control. The distribution of propositi by maternal age, born during the years 1938-1956, was compared with the expected distribution calculated from the New York State white live-born children for the same years. Table III presents the observed and expected numbers in relation to maternal age-groups. There was a deficiency of propositi born to mothers at ages 1524 years, and an excess at maternal ages $30-39$ years (Fig. 1). The deviation between the observed and expected values is statistically significant, $p<0.001$. When male and female propositi are compared to each other, there is an excess of males born to mothers 35-39 years (Fig. 2). 


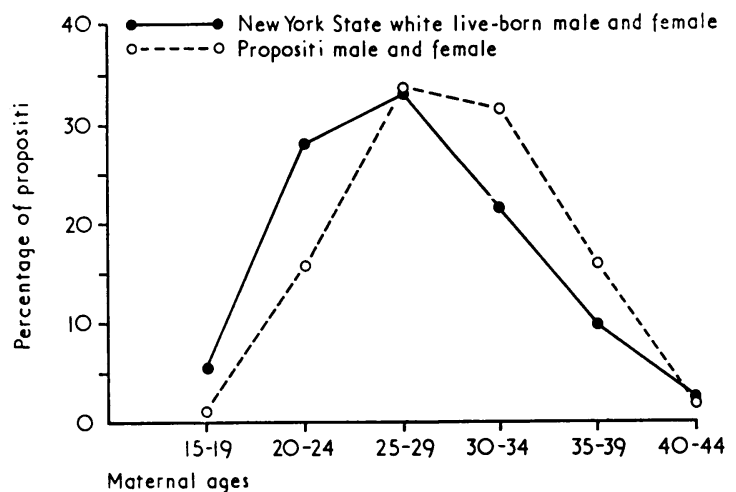

FIg. 1. Maternal age distribution of propositi and New York State white live births.

An excess of propositi born at later maternal ages might be expected to be reflected in birth order. The birth orders of the propositi were compared to the expected figures (N.Y. State) for the same years (Table IV). There was a statistically significant difference, $\chi^{2}=24.87,4$ d.f., $\mathrm{p}<0.001$, between the observed and expected distribution of propositi by birth order, indicating an excess of first-born. All first-born propositi then were arranged according to their distribution by maternal ages and compared to the expected figures from the New York State first-born (Table V). The excess of first-born at maternal ages 30-39 years parallels the excess of propositi in the same maternal age-groups. This is not consistent with the conventional association of a higher birth order with a high maternal age. Therefore, the method of Greenwood and Yule (1914) was applied, which tests for birth order effect in relation to sibship size. Using this method to test only complete sibships with all sibs over 16 years of age, an excess of affected individuals at higher birth orders was noted $\left(\chi^{2}=17 \cdot 53,7\right.$ d.f., $\left.\mathrm{p}=0 \cdot 015\right)$.

TABLE IV

DISTRIBUTION OF PROPOSITI BY BIRTH ORDER

\begin{tabular}{|c|c|c|}
\hline \multirow{2}{*}{ Birth Order } & \multicolumn{2}{|c|}{ Propositi* } \\
\hline & Observed & Expected \\
\hline $\begin{array}{l}1 \\
2 \\
3 \\
4 \\
5 \text { and over }\end{array}$ & $\begin{array}{r}191 \\
137 \\
45 \\
16 \\
11\end{array}$ & $\begin{array}{r}159 \\
127 \\
61 \\
26 \\
27\end{array}$ \\
\hline Total & 400 & 400 \\
\hline
\end{tabular}

$x^{2}=24 \cdot 87,4$ d.f., $\mathrm{p}<0.001$.

* Observed and expected values calculated from data of Table III. There were four propositi without birth order information.

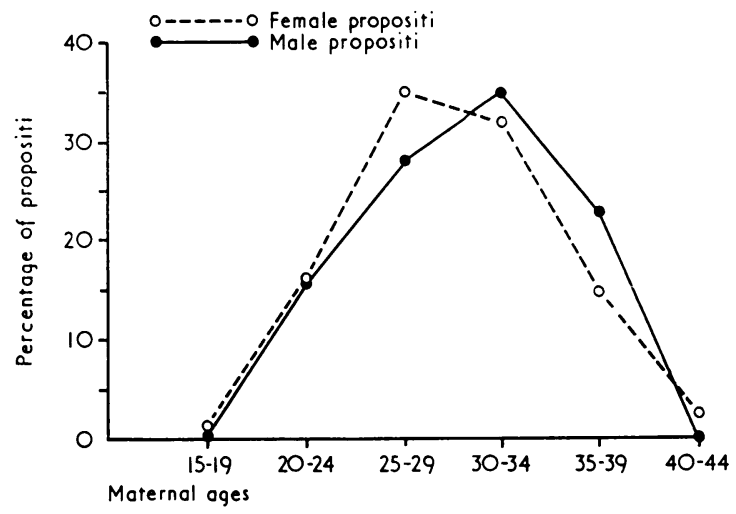

Fig. 2. Maternal age distribution of male and female propositi.

The results of the two different methods of testing birth order, and the relation of birth order to maternal age, suggested the following analysis. Propositi were divided into two groups: those with one or more affected sibs (Group I), and those without affected sibs (Group II). To insure against potentially affected sibs in Group II sibships, only mothers 44 years or over (accepted as essentially having completed their reproductive performance), and only sibships with all sibs over the age of 16 years were included in the subsequent analysis. Mean maternal ages then were calculated for the propositi in the two groups (Table VI). In both male and female samples the mean maternal ages of propositi having affected sibs (Group I) is significantly lower than that of propositi without affected sibs (Group II), p < 0.01 (Fig. 3).

In view of this maternal age difference between the two groups and the implied excess of first-born propositi to mothers over the age of 30 years (Table V), the sibship size in the two sets of propositi was compared using only completed sibships (mothers 44 years or over). While the male sample was too

TABLE V

DISTRIBUTION OF PROPOSITI OF FIRST BIRTH ORDER BY MATERNAL AGE

\begin{tabular}{c|c|c}
\hline & \multicolumn{2}{|c}{ Numbers of First-born Propositi } \\
\cline { 2 - 3 } Maternal Age-group & Observed & Expected \\
\hline $15-19$ & 4 & 21 \\
$20-24$ & 53 & 80 \\
$25-29$ & 69 & 58 \\
$30-34$ & 48 & 23 \\
$35-39$ & 17 & 8 \\
$40-44$ & 0 & 1 \\
\hline Total & 191 & 191 \\
\hline
\end{tabular}

$x^{2}=63 \cdot 10,5$ d.f., $\mathrm{p}<0 \cdot 001$. 


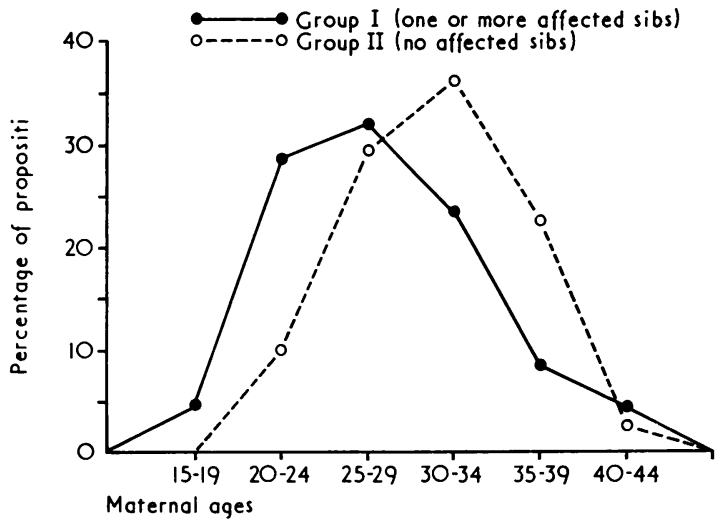

FIG. 3. Maternal ages at births of Group I and Group II propositi.

small to interpret, an analysis of the mean sibship size of the female sample revealed differences between the two groups. Sibships of propositi without affected sibs were significantly smaller, $1 \cdot 29$, than those having affected sibs, $2 \cdot 34, t=3 \cdot 34$, d.f. $=248, p<0.01$, as anticipated from the maternal age differences.

Twin Sample. The 14 twin pairs within the total study population were studied regarding zygosity and scoliosis status. The spine radiographs of each twin were reviewed, employing

TABLE VI

MEAN MATERNAL AGES OF PROPOSITI WITH AND WITHOUT AFFECTED SIBS

\begin{tabular}{|c|c|c|c|c|c|c|}
\hline \multicolumn{7}{|c|}{ Maternal Ages } \\
\hline \multirow{2}{*}{ Propositi } & \multicolumn{2}{|c|}{ Group I* } & \multicolumn{2}{|c|}{ Group IIt } & \multirow{2}{*}{ t } & \multirow{2}{*}{$\mathbf{p}$} \\
\hline & No. & Mean & No. & Mean & & \\
\hline $\begin{array}{l}\text { Male } \\
\text { Female }\end{array}$ & $\begin{array}{r}9 \\
38\end{array}$ & $\begin{array}{l}26 \cdot 3 \\
28 \cdot 3\end{array}$ & $\begin{array}{r}37 \\
218\end{array}$ & $\begin{array}{l}31.4 \\
30.9\end{array}$ & $\begin{array}{l}4 \cdot 21 \\
2 \cdot 68\end{array}$ & $\begin{array}{l}<0.01 \\
<0.01\end{array}$ \\
\hline
\end{tabular}

* Propositi with affected sibs.

+ Propositi without affected sibs.

TABLE VII

TWIN PAIRS BY SEX, ZYGOSITY, AND CONCORDANCE-DISCORDANCE CLASSIFICATION FOR SCOLIOSIS

\begin{tabular}{|c|c|c|c|}
\hline Zygosity & Sex & No. of Pairs & $\begin{array}{l}\text { Concordance- } \\
\text { discordance } \\
\text { Classification }\end{array}$ \\
\hline $\begin{array}{l}\text { Monozygotic } \\
\text { Dizygotic (like-sex) } \\
\text { Dizygotic (unlike-sex) }\end{array}$ & $\begin{array}{ll}\mathbf{F} & \mathbf{F} \\
\mathbf{M} & \mathbf{M} \\
\mathrm{F} & \mathbf{F} \\
\mathbf{M} & \mathbf{F} \\
\mathbf{M} & \mathbf{F}\end{array}$ & $\begin{array}{l}6 \\
1 \\
3 \\
3 \\
1 \\
1\end{array}$ & $\begin{array}{l}\text { Concordant } \\
\text { Concordant } \\
\text { Concordant } \\
\text { Concordant } \\
\text { Discordant } \\
\text { Unclassified }\end{array}$ \\
\hline
\end{tabular}

* One pair established from previous medical record.

† Female co-twin has leg length discrepancy. the generally accepted criteria for the diagnosis of structural scoliosis, i.e. any measurable lateral spinal curvature associated with vertebral wedging or rotation. On this basis twin pairs were classified as concordant (both members affected with scoliosis) or discordant (only one member affected). One unlike sex twin pair refusing participation was confirmed concordant from the medical record. Table VII presents the twin pairs by zygosity, sex, and concordance-discordance classification. All monozygotic and all like sex dizygotic twin pairs were concordant, and among the unlike sex dizygotic twin pairs, three were concordant and one was discordant for scoliosis. One pair of unlike sex dizygotic twins could not be classified due to leg length discrepancy of the female co-twin.

Among the propositi, 19 twin subjects were identified. There were 13 twins included in the 510 patients polled by questionnaire (Table I), and 2 and 4 twins were noted through the medical records of the unanswered and undelivered questionnaire categories, respectively. The latter two categories must be considered unpolled, therefore the twin incidence in these groups cannot be interpreted. Among the patients replying to the twin question, $2.5 \%$ were found to be twins. While the foregoing data were confined to twins among the propositi, the twin frequency in the sibships of all propositi also was calculated. 38 twin pairs or 76 twin subjects were identified among 3069 total births in all sibships, giving a twin frequency of $1: 40 \cdot 4$, or $2 \cdot 5 \%$.

\section{Discussion}

Previous studies have suggested a dominant mode of inheritance for scoliosis (Faber, 1936; WynneDavies, 1965). Since dominant inheritance usually is characterized by every affected child having an affected parent, the data of this study do not give evidence supporting this pattern of inheritance (Table II). Employing the simple sib method as a test for recessive inheritance to the sibships with all members over age 16 years, instead of the $3: 1$ ratio of unaffected to affected sibs that is expected, a 10.7:1 ratio is observed. Therefore, the data of this study do not provide evidence for a simple and predictable pattern of inheritance in idiopathic scoliosis.

Another method of testing for an increased incidence among relatives of propositi is to compare the latter with the frequency in the general population. The report of Shands and Eisberg (1955) provides the most appropriate general population scoliosis incidence information. It is recognized that their incidence figure of $1.8 \%$ from 50,000 
tuberculosis survey radiographs is low due to techniques employed and the exclusion of the lumbar spine from the radiographic field. Since the information regarding the presence or absence of scoliosis in the present study was more reliable for the sibs than for the parents of the propositi, only sib data were used for comparison to the general population incidence. In males, 5 of 72 , or $7 \%$, and in females, 35 of 357 , or $10 \%$ sibs were affected with scoliosis; the observed numbers of affected sibs are significantly higher than the 1.3 and 6.4 expected for males and females, respectively. This finding indicates that either genetic factors, or environmental influences more frequently shared by sibs than by persons in the general population, are important in the occurrence of idiopathic scoliosis.

Twin investigations are of value in distinguishing between these two alternative explanations, genetic or environmental. There were four previous twin studies of idiopathic scoliosis: Verschuer (1927) reported six pairs, Schokking (1931) 4 pairs, Nitsche and Armknecht (1933) 5 pairs, and Faber (1936) 5 pairs of twins. In these studies, pairs were classified as discordant for scoliosis while in the age range of maximum likelihood for development of the condition and without radiographic evidence. Therefore, the results of these studies cannot be interpreted.

In this study an effort to ascertain all twin individuals in this scoliosis population was made, and all available twin pairs were studied without selection on the basis of sex, zygosity, or scoliosis status of the co-twins. All 6 monozygotic twin pairs and all 4 like-sex dizygotic pairs were concordant for scoliosis. Among the 4 unlike-sex dizygotic twins, there were 3 pairs concordant and 1 pair discordant for scoliosis. The comparable concordance observed between monozygotic and dizygotic twin pairs argues against not only a simple mode of inheritance, but also polygenic inheritance, unless the genes are extremely common in the general population. That both members of likesex dizygotic twin pairs are found to have scoliosis as frequently as both members of monozygotic twin pairs indicates that there are factors to which both types of twins are exposed that influence the occurrence of scoliosis. Since both members of a twin pair share simultaneously the same intrauterine environment, these results indicate that maternal factors are important in scoliosis. This interpretation, furthermore, is compatible with the suggestion of an increased incidence of affected sibs relative to the incidence in the general population.

Corresponding twin frequencies of $2.5 \%$ were observed among patients who were polled, and among sibships of the propositi. The only available general population twin incidence figure for comparison is that of Allen (1955). The proportion of twins in the sibships is significantly greater $\left(\chi^{2}=5 \cdot 48,1\right.$ d.f., $\left.\mathrm{p}=0.02\right)$ than the expected $1.9 \%$. Furthermore, it may be assumed that these twin proportions are minimal, since only intact pairs were identified. (A detailed analysis of the twin study will be presented in a separate report.) In these data, therefore, there is an excess of twins in the sibships of the propositi and a suggestion that twins are prone to scoliosis. Since there is an increased frequency of twinning at higher maternal ages, 35-40 years, the results suggest that mothers of scoliosis offspring are having an excess of pregnancies at later ages. If higher maternal ages are associated with scoliosis offspring, this could account for the increase of affected twins.

The propositi comprising the answered group were included in this analysis and, in so far as could be determined, they represent an unbiased sample from a totally ascertained idiopathic scoliosis population. This analysis reveals that a statistically significant excess of propositi was born to mothers over 30 years of age. However, two populations of mothers were discerned (Table VI): Group I, those with more than one affected offspring begin having children at a relatively younger age and have larger families; and, Group II, those with only one affected offspring begin having children at a relatively later age, and consequently have significantly smaller families. The statistically significant excess of first-born propositi and at maternal ages 30-39 years accounts for the much larger proportion in Group II. Complete information is not available for either group of mothers regarding abortions, stillbirths, and fertility problems. Such information would make it possible, not only to evaluate the reproductive performance of these mothers, but also to clarify the maternal age and family size differences between these two groups of mothers. There was no suggestion in these data that affected parents alter the mean maternal age in either group.

The marked preponderance of females affected with idiopathic scoliosis is well known (Cobb, 1943; Kleinberg, 1951; Steindler, 1929). In an effort to identify differences between the two sexes which may be related to the unequal sex ratio in scoliosis, males and females were analysed separately in this study. An analysis of the sex ratios in the completed sibships revealed no deviation from the expected 1:1 sex ratio, except in the sibships of male propositi without affected sibs. In the latter category there were 40 male and 18 female sibs, which is a 
significant deviation from the $1: 1$ sex ratio $\left(\chi^{2}=8 \cdot 34\right.$, 1 d.f., $\mathrm{p}<0.005)$. It also should be noted that in the comparison of males and females by maternal age distribution an excess of male propositi born to mothers 35-39 years was observed. Actually, a deficiency of males was anticipated (Novitski and Kimball, 1958) in view of the higher maternal age and low birth order represented in this group, and on the basis of the high correlation between parental ages. In this study, the mean parental ages were 33.21 years for fathers and 29.67 years for mothers. While the above sample showing the abnormal sex ratio favouring males is small, it does occur in the sibships of male propositi characterized as having a higher maternal age. From these data there is no evidence of selection against males to account for the disproportionate number of females with scoliosis. In fact, these data imply that there are even maternal factors favouring males with or without scoliosis at higher maternal ages from these mothers.

A raised maternal age is well known to be associated with Down's syndrome (mongolism) (Penrose, 1963). It is of interest, moreover, that in Down's syndrome there are also two populations of mothers, one having affected offspring at any age, and the other primarily at older ages. There is an increased frequency of second affected offspring among the former group. While the latter parallel exists between the mothers of mongol and of scoliosis offspring, this does not imply that the maternal factors are of the same nature in both conditions.

Investigations of other abnormalities have demonstrated genetic and environmental influences. In spite of the instances in which central nervous system malformations have been attributed to genetic factors, usually they occur without known causes. Ingalls, Pugh, and MacMahon (1954) reported a high incidence of spina bifida, and hydrocephalus (as grouped separately by these investigators) associated with first births at ages 35 and over. They conclude that birth order effect in spina bifida, and maternal age effect in hydrocephalus are the most prominent associations in their data. In a study of congenital dislocation of the hip, Record ard Edwards (1958) noted that the incidence of the defect in first-born rose with increasing maternal age, and the incidence was high at ages 35 and over. They also found associations with breech deliveries and births in the winter months. These authors suggest that multifactorial inheritance and a number of environmental factors determine this abnormality. The maternal age and birth order findings in these studies correspond with those in the present report, but the results of twin studies on these abnormalities differ from those in idiopathic scoliosis.
In a twin study of central nervous system malformations (Record and McKeown, 1951), 91\% of the number of pairs estimated to be monozygotic (Fogel, Nitowsky, and Gruenwald, 1965) and 100\% of the dizygotic pairs were discordant for the abnormality. Among twins with congenital dislocation of the hip, Idelberger (1951) found $59 \%$ of the monozygotic and $97 \%$ of the dizygotic pairs discordant. Biases in the latter study would result in an over-representation of concordant monozygotic pairs. Nevertheless, the high frequency of discordant monozygotic pairs with central nervous system malformations and congenital dislocation of the hip makes it apparent that environmental influences are of aetiological significance in these abnormalities.

In this study of idiopathic scoliosis there is no evidence for a simple genetic component. While the increased incidence in sibs relative to the general population suggests multifactorial inheritance, the high concordance observed among dizygotic twin pairs is not in accord with this interpretation. These findings are consistent with maternal effect, since both members of a dizygotic pair simultaneously share the same maternal environments and, in general, sibs are exposed to more similar maternal factors than are unrelated persons. There is no information in these data to indicate whether the maternal influences are predominantly of a physiological nature or relate to physical uterine conditions. However, it is noteworthy that there are mothers aged 25 years and under, though relatively few in number, who may have characteristics in common with mothers 35 years and over, such that their firstborn offspring are most susceptible to developing the same abnormality. Of course it cannot be assumed that the maternal effects are the same at all maternal ages or in all cases.

\section{Summary}

In this study there was no evidence in support of a simple genetic basis for idiopathic scoliosis. The high concordance in both monozygotic and dizygotic twin pairs suggests that maternal influences predominate; the increased incidence of affected sibs is consistent with this reading.

The finding of a statistically significant excess of propositi born to mothers ages 30-39 years relates these maternal factors predisposing to scoliosis to increased maternal age. This was especially noted in a predominance of affected males born to mothers at ages 35-39. That the mothers of scoliosis patients are having an excessive number of pregnancies at higher maternal ages is reflected in the finding of an increased frequency of twins among the sib- 
ships of the propositi and an increased number of twins with idiopathic scoliosis.

Although a significant excess of propositi were first-born, differences in maternal age and sibship size were noted between propositi with affected sibs and those without affected sibs. In addition, a preponderance of males was observed among the sibships of male propositi without affected sibs.

The authors are very grateful to Professor Richard H. Osborne, Department of Medical Genetics, University of Wisconsin, for his helpful discussions and for reading the manuscript.

This work was supported in part by a grant in aid from the National Foundation; and U.S. Public Health Service General Research Support Grant FR-5495 from the Division of Research Facilities and Resources; by Training Grant AM 5414 from the National Institute of Arthritis and Metabolic Diseases.

\section{REFERENCES}

Allen, G. (1955). Comments on the analysis of twin samples. Acta Genet. (Roma), 4, 143.

American Orthopedic Association Research Committee (1941). End-result study of the treatment of idiopathic scoliosis. $\mathcal{F}$. Bone ft Surg., 23A, 963.

Cobb, J. R. (1943). Treatment of scoliosis. Conn. med. F., 7, 467.

- (1948). Outline for the study of scoliosis. Instruct. Course Lect. Amer. Acad. orthoped. Surg., 5, 261.

Faber, A. (1936). Untersuchungen über die Erblichkeit der Skoliose. Arch. orthop. Unfall-Chir., 36, 217.

Fogel, B. J., Nitowsky, H. M., and Gruenwald, P. (1965). Discordant abnormalities in monozygotic twins. F. Pediat., 66, 64.

Garland, H. G. (1934). Hereditary scoliosis. Brit. med. f., 1, 328.

Greenwood, M., and Yule, G. U. (1914). On the determination of size of family and of the distribution of characters in order of birth from samples taken through members of the sibships. f. roy. Statist. Soc., 77, 179.

Idelberger, K. (1951). Die Erbpathologie der sogenannten angeborenen Hüftverrenkung. Urban und Schwarzenberg, Munich.

Ingalls, T. H., Pugh, T. F., and MacMahon, B. (1954). Incidence of anencephalus, spina bifida, and hydrocephalus related to birth rank and maternal age. Brit. F. prev. soc. Med., 8, 17.

Kleinberg, S. (1951). Scoliosis: Pathology, Etiology and Treatment, 2nd ed. Williams and Wilkins, Baltimore.

Li, C. C. (1961). Human Genetics. McGraw-Hill, New York.

McCarroll, H. R., and Costen, W. (1960). Attempted treatment of scoliosis by unilateral vertebral epiphysial arrest. F. Bone ft Surg., 42A, 965.

Molski, K. (1957). Rodzinne skrzywienie kregosupa. Chir. Narzad. Ruchu, 22, 117.

Nitsche, F., and Armknecht, P. (1933). Orthopädische Leiden bei Zwillingen. Z. orthop. Chir., 58, 518.

Novitski, E., and Kimball, A. W. (1958). Birth order, parental ages, and sex of offspring. Amer. F. hum. Genet., 10, 268.

Osborne, R. H., and De George, F. V. (1959). The Genetic Basis of Morphological Variation. Harvard University Press, Cambridge, Mass.

Penrose, L. S. (1963). The Biology of Mental Defect, 3rd ed. Grune and Stratton, New York.

Record, R. G. and Edwards, J. H. (1958). Environmental influences related to the aetiology of congenital dislocation of the hip. Brit. f. prev. soc. Med., 12, 8.

$\longrightarrow$, and McKeown, T. (1951). Congenital malformations of the central nervous system: data on sixty-nine pairs of twins. Ann. Eugen. (Lond.), 15, 285.

Riddle, H. F. V., and Roaf, R. (1955). Muscle imbalance in the causation of scoliosis. Lancet, 1,1245 .

Schokking, C. P. (1931). Uitbreiding van het Tweelingonderzoek in Nederland. P. J. Mulder, Leyden.

Shands, A. R., and Eisberg, H. B. (1955). The incidence of scoliosis in the state of Delaware. A study of 50,000 minifilms of the chest made during a survey for tuberculosis. f. Bone $f t$ Surg., 37A, 1243.

Sidler, A. (1938). Beitrag zur Kenntnis der familiären Skoliose. Schweiz. med. Wschr., 68, 362.

Staub, H. A. (1922). Eine Skoliotikerfamilie. Ein Beitrag zur Frage der kongenitalen Skoliose und der Heredität der Skoliosen. Z. orthop. Chir., 43, 1.

Stearns, G., Jo-Yun Tung Chen, McKinley, J. B., and Ponseti, I. V. (1955). Metabolic studies of children with idiopathic scoliosis. f. Bone ft Surg., 37A, 1028.

Steindler, A. (1929). Diseases and Deformities of the Spine. C. V. Mosby, Saint Louis.

Verschuer, O. (1927). II. Die verebungsbiologische Zwillingsforschung. Ihre biologischen Grundlagen. Ergebn. inn. Med. Kinderheilk., 31, 35.

Wynne-Davies, R. (1965). Familial scoliosis. In Proceedings of a Symposium on Scoliosis, ed. P.A. Zorab, p. 3ó. National Fund for Research into Poliomyelitis, London. 